\section{Seizure Disorders at Madonna University Teaching Hospital; Prevalence, Patterns and Co-Morbidities - A 7 Year Review}

\section{Abstract}

Objective: The study was designed to study the prevalence, patterns and comorbidities of seizure disorders among psychiatric clinic attendees at Madonna University Teaching Hospital, Elele, Rivers State, Nigeria, over a 7-year period.

Materials and Methods: Case files of all psychiatric patients who attended the psychiatric clinic of Madonna University Teaching Hospital (MUTH) from June 2011 to June 2018 were revived. Records of patients who had a diagnosis of seizure disorder were studied.

Results: A total of 2,283 patients attended the psychiatric clinic within the time frame stated. Out of this, 148 were diagnosed with a seizure disorder, hence giving a prevalence of $6.5 \%$. The largest proportions of the subjects were aged $21-30$ years (33.1\%), female $(54.1 \%)$, single $(71.6 \%)$ and had a secondary education $(39.9 \%)$. Tonic clinic seizure was the most prevalent seizure type (55.4\%). Most of the patients had neither medical (70.3\%) nor psychiatric co-morbidity (60.8\%). Temporal lobe epilepsy had the highest psychiatric co-morbidity $(91.7 \%)$ and the most common psychiatric co-morbidity was Depression (16.2\%). The association between seizure type and psychiatric co-morbidity was statistically significant $(\chi 2=22.388, \mathrm{df}=8$, $\mathrm{p}<0.05)$.

Conclusion: Tonic-clonic seizure was the most prevalent seizure type seen but those suffering from temporal lobe epilepsy had the highest rate of psychiatric morbidity. Depression was the most common psychiatric co-morbidity among epileptic patients and seizure patients have the tendency to develop another medical condition as they grow older.

Keywords: Epilepsy; Seizure; Disorder; Psychiatry; Co-morbidity

\section{Chidozie Donald Chukwujekwu*}

Department of Neuropsychiatry, University of Port Harcourt Teaching Hospital, Port Harcourt, Rivers State, Nigeria

\section{*Corresponding author: \\ Chidozie Donald Chukwujekwu \\ ” chidozie.chukwujekwu@uniport.edu.ng \\ Department of Neuropsychiatry, University of Port Harcourt Teaching Hospital, Port Harcourt, Rivers State, Nigeria.}

Tel: 08035928593

Citation: Chukwujekwu CD (2019) Seizure Disorders at Madonna University Teaching Hospital; Prevalence, Patterns and Co-Morbidities - A 7 Year Review. Clin Psychiatry Vol.5 No.1:3

Received: February 12, 2019; Accepted: March 25, 2019; Published: April 01, 2019

\section{Introduction}

Epilepsy can be defined as a chronic, episodic, neurological disorder characterized by the spontaneous and unpredictable manifestation of seizures [1]. It is the commonest neurological disorder encountered in sub-Saharan African and is associated with significant morbidity and mortality as well as diverse sociocultural, psychological and economic implications [2-4].

The burden of epilepsy on the healthcare system is quite huge and studies have reported burdens of epilepsy in African children ranging between 7.3 per 1000 in South African and 41 per 1000 is Kenya [5,6].
Globally it is estimated that 70 million people suffer from epilepsy and the global prevalence of epilepsy is estimated to be 5.9 per 1000 population [7]. Based on Global Burden of Disease analysis for 2010 , epilepsy accounted for $0.7 \%$ of the global burden or more than 17 million DALYS [7].

Although some studies have been done in Nigeria to ascertain the prevalence of the disorder, with rates ranging between $4.3 / 1000$ -6.0/1000 reported [8-10], most of those studies are old and none has been done in the Niger Delta region of Nigeria. Port Harcourt, the capital of Rivers State with the environs is the hub of the Niger Delta region of Nigeria; it is cosmopolitan, hosting several ethnic nationalities and people from other parts of the 
world. Therefore the need to replicate these studies in Rivers State is imperative, as the results that would be derived will be sufficiently representative of the Nigerian people.

The aim of this study is to assess the prevalence and patterns of seizure disorders as well as the associated co-morbidities in patients who attended the Madonna University Teaching Hospital over a seven year period. The result of this study will help us understand the enormity of this health challenge in the Niger Delta Region of Nigeria and will be invaluable to policy makers as well as health care providers.

\section{Methodology}

This retrospective study was conducted at the Madonna University teaching Hospital (MUTH), Elele over a four month period (July-October 2018). The Madonna University Teaching Hospital is a 700-bed Catholic Teaching Hospital located in Elele, Rivers State of Nigeria.

Case files of all patients who attended the psychiatric clinic of Madonna University Teaching Hospital (MUTH), Elele from June 2011 to June 2018 were reviewed. These medical records were domiciled in the records department of the institution. The medical records department is adjacent to the psychiatric department in the hospital complex. The institution's medical librarian assisted by three library assistants retrieved the files for the researcher from the file rack where they were stacked. Starting with the files of the psychiatric patients who came to the hospital on June $1^{\text {st }} 2011$, more than one hundred and twenty five files were reviewed weekly by the researcher within the study period. All patients who had a diagnosis of seizure disorder or epilepsy were enlisted in the study. Their socio-demographic variables, types of seizures as well as their documented medical and psychiatric co-morbidities were derived from the case files included in the study. Psychiatric diagnoses were derived from the case files included in the study. Psychiatric diagnoses were documented based on the ICD-IO criteria. Classification of seizure was in accordance with the International League against Epilepsy \{ILAE\}, 1981 (see Appendix).

Before the commencement of this study, approval of the ethical committee of Madonna University Teaching Hospital (MUTH) was obtained. The data was analyzed using the Statistical Package for Social Sciences (SPSS) version 16 at $5 \%$ level of significance and $95 \%$ confidence interval.

Frequencies of the various variables were displayed using frequency distribution tables. Tests of significance and proportions of categorical parameters were analyzed with the chi-square test.

\section{Results}

Out of a total of 2,283 patients who attended the psychiatric clinic of the Madonna University Teaching Hospital within the study period, one hundred and forty eight (148) patients were diagnosed with seizure disorders and therefore assessed. Therefore the percentage of seizure disorder in the cohort was $6.5 \%$.
The minimum age of the patients was 12 years and the maximum, 79 years. The mean age of the subjects was 30.4 years \pm 13.5 years.

Table 1 depicts the distribution of the frequencies of the sociodemographic and clinical variables. The largest categories of the patients were young, belong to age categories $21-30$ years (33.1\%) and $11-20$ years $(29.7 \%)$, female $(54.1 \%)$, single $(71.6 \%)$, and had secondary education (39.9\%).

Furthermore, tonic-clonic seizure was the most prevalent type (55.4\%) seen among the subjects. Most of the patients had neither medical (70.3\%) nor psychiatric co-morbidity $(60.8 \%)$. However, among the medical co-morbidities, the most common was Hypertension (6.8\%) while Depression (16.2\%) was the most common psychiatric co-morbidity (Table 1).

Table 2 displays the association between seizure type and having another medical condition. Even though one patient (100\%) with myoclonic seizure had another medical condition and $58.3 \%$ of patients with temporal lobe seizure constituted the largest percentages of the seizure types with another medical condition, there is no statistically significant difference between having a particular seizure type and having a medical co-morbidity (Table 2).

Table 3 shows the association between seizure type and psychiatric co-morbidity. Comparatively, $91.7 \%$ of subjects with temporal lobe seizures, $55.6 \%$ of subjects with complex partial seizure, $54.5 \%$ of subjects with atonic seizures and $50 \%$ of subjects with tonic seizures had a psychiatric co-morbidity. Furthermore the association between seizure type (especially temporal lobe epilepsy) and psychiatric co-morbidity is statistically significant (Table 3).

Table 4 depicts the association between socio-demographic variables and having another medical condition. The age categories with relatively the largest percentages of subjects with another medical condition were those aged between 41-50 years $(81.8 \%), 51-60$ years $(77.8 \%)$ and $31-40$ years $(48.3 \%)$ and there is statistically significant difference between subjects aged between 11-20 years and those aged between $41-50$ years and older in developing a medical condition. Similarly, all those that were separated or divorced had another medical condition and there is statistically significant difference in developing a medical condition between these subjects and the unmarried (Table 4).

Table 5 shows the association between socio-demographic variables and psychiatric co-morbidity. The subgroups with the largest psychiatric co-morbidities were subjects greater than 60 years old $(66.7 \%)$, males $(45.6 \%)$, those separated or divorced (75.0\%) and those with tertiary education (60.9\%). Nevertheless there was no statistical difference between the various subcategories of each socio-demographic variable in developing psychiatric co-morbidity (Table 5).

\section{Discussion}

In sub-Saharan Africa, epilepsy is mainly secondary to adverse perinatal events and untoward neuropsychiatric sequale of 
Table 1 Frequency Table of the socio-demographic and clinical variables $(\mathrm{N}=148)$.

\begin{tabular}{|c|c|c|}
\hline & $\begin{array}{l}\text { Frequency } \\
\text { (n) }\end{array}$ & $\begin{array}{c}\text { Prevalence } \\
\text { (\%) }\end{array}$ \\
\hline \multicolumn{3}{|l|}{ Age (years) } \\
\hline $11-20$ & 44 & 29.7 \\
\hline $21-30$ & 49 & 33.1 \\
\hline $31-40$ & 29 & 19.6 \\
\hline $41-50$ & 11 & 7.4 \\
\hline $51-60$ & 9 & 6.1 \\
\hline$>60$ & 6 & 4.1 \\
\hline \multicolumn{3}{|l|}{ Sex } \\
\hline Male & 68 & 45.9 \\
\hline Female & 80 & 54.1 \\
\hline \multicolumn{3}{|l|}{ Marital status } \\
\hline Single (Unmarried) & 106 & 71.6 \\
\hline Married & 32 & 21.6 \\
\hline Separated/Divorced & 4 & 2.7 \\
\hline Widowed & 6 & 4.1 \\
\hline \multicolumn{3}{|l|}{ Literacy Status } \\
\hline Illiterate & 43 & 29.1 \\
\hline Primary Education & 23 & 15.5 \\
\hline Secondary education & 59 & 39.9 \\
\hline Tertiary Education & 23 & 15.5 \\
\hline \multicolumn{3}{|l|}{ Seizure Type } \\
\hline Tonic Clonic & 82 & 55.4 \\
\hline Tonic & 8 & 5.4 \\
\hline Akinetic/Atonic & 11 & 7.4 \\
\hline Absence & 5 & 3.4 \\
\hline Myoclonic & 1 & 0.7 \\
\hline Simple Partial & 6 & 4.1 \\
\hline Complex Partial & 9 & 6.1 \\
\hline Temporal Lobe Epilepsy & 12 & 8.1 \\
\hline Partial Seizure Secondarily generalized & 14 & 9.5 \\
\hline \multicolumn{3}{|l|}{ Medical Comorbidity } \\
\hline Hypertension & 10 & 6.8 \\
\hline Diabetes & 6 & 4.1 \\
\hline Cerebrovascular Accident & 5 & 3.4 \\
\hline Asthma & 2 & 1.4 \\
\hline Peptic Ulcer Disease & 3 & 2.0 \\
\hline Human Immunodeficiency Virus infection & 5 & 3.4 \\
\hline Cancers/Other tumors & 4 & 2.7 \\
\hline Head ache/Migraine & 2 & 1.4 \\
\hline Other medical conditions & 7 & 4.7 \\
\hline Nill medical co-morbidity & 104 & 70.3 \\
\hline \multicolumn{3}{|l|}{ Psychiatric Co-morbidity } \\
\hline Panic disorder & 5 & 3.4 \\
\hline Depression & 24 & 16.2 \\
\hline Conversion disorder & 2 & 1.4 \\
\hline Anxiety Disorder & 13 & 8.8 \\
\hline Schizophrenia-like psychotic disorder & 10 & 6.8 \\
\hline Mania & 2 & 1.4 \\
\hline Delusional Disorder & 2 & 1.4 \\
\hline \multirow[t]{2}{*}{ Nil Psychiatric Co-morbidity } & 90 & 60.8 \\
\hline & 1 & 100 \\
\hline
\end{tabular}

Table 2 Association between seizure type and having another medical condition ( $\mathrm{N}=148)$.

\begin{tabular}{|c|c|c|c|c|c|c|}
\hline Seizure Type & $\begin{array}{l}\text { With } \\
\text { Another } \\
\text { Med. } \\
\text { Condition } \\
\text { n (\%) }\end{array}$ & $\begin{array}{l}\text { Without } \\
\text { Another } \\
\text { Med. } \\
\text { Condition } \\
\text { n (\%) }\end{array}$ & Total & $\chi^{2}$ & df & $p$ value \\
\hline Tonic-Clonic & $20(24.4)$ & $62(75.6)$ & 82 & 12.572 & 8 & 0.127 \\
\hline Tonic & $4(50.0)$ & $4(50.0)$ & 8 & & & \\
\hline Akinetic/Atonic & $2(18.2)$ & $9(81.8)$ & 11 & & & \\
\hline Absence & $1(20.0)$ & $4(80.0)$ & 5 & & & \\
\hline Myoclonic & $1(100)$ & $0(0)$ & 1 & & & \\
\hline Simple Partial & 1 (16.7) & $5(83.3)$ & 6 & & & \\
\hline Complex partial & $2(22.2)$ & $7(77.8)$ & 9 & & & \\
\hline $\begin{array}{l}\text { Temporal Lobe } \\
\text { Seizure }\end{array}$ & 7 (58.3) & 5 (41.7) & 12 & & & \\
\hline $\begin{array}{l}\text { Partial Seizure } \\
\text { Secondarily } \\
\text { Generalized }\end{array}$ & 6 (42.9) & (857.1) & 4 & & & \\
\hline
\end{tabular}

Table 3 Association between seizure type and psychiatric comorbidity $(\mathrm{N}=148)$.

\begin{tabular}{|c|c|c|c|c|c|c|}
\hline Seizure Type & $\begin{array}{c}\text { With } \\
\text { Psychiatric } \\
\text { Comorbidity } \\
\text { n (\%) }\end{array}$ & $\begin{array}{c}\text { Without } \\
\text { psychiatric } \\
\text { comorbidity } \\
\text { n (\%) }\end{array}$ & Total & $x^{2}$ & df & $p$ value \\
\hline Tonic-Clonic & $26(31.7)$ & $56(68.3)$ & 82 & & & \\
\hline Tonic & $4(50.0)$ & $4(50.0)$ & 8 & & & \\
\hline Akinetic/Atonic & $6(54.5)$ & $5(45.5)$ & 11 & & & \\
\hline Absence & $1(20.0)$ & $4(80.0)$ & 5 & & & \\
\hline Myoclonic & $1(100)$ & $0(0)$ & 1 & & & \\
\hline Simple Partial & 1 (16.7) & $5(83.3)$ & 6 & & & \\
\hline Complex partial & $5(55.6)$ & $4(44.4)$ & 9 & & & \\
\hline $\begin{array}{l}\text { Temporal Lobe } \\
\text { Seizure }\end{array}$ & 11 (91.7) & $1(8.3)$ & 12 & 22.388 & 8 & $0.004 *$ \\
\hline Partial Seizure & $4(28.6)$ & $10(71.4)$ & 14 & & & \\
\hline \multicolumn{7}{|c|}{$\begin{array}{l}\text { Secondarily } \\
\text { generalized }\end{array}$} \\
\hline *Significant at $p$ & $<0.05$ & & & & & \\
\hline
\end{tabular}

diverse microbial insult during childhood and thereafter [11].

The mean age of the subjects in this study was 30.4 years \pm 13.5 years. This is a younger mean age compared to the result from a study carried out by Moran et al. in the United Kingdom in which a mean age of 55.2 years was reported [12].

The prevalence of seizure disorders among the psychiatry clinic attendees was $6.5 \%$. This is much higher than prevalence of seizure reported among the general population in literature [810,13 ] but it should be noted that these studies were carried out among the general population and not among psychiatric hospital attendees.

This study shows that the majority of the subjects included females (54.9\%) and those who had at least a secondary 
Table 4 Association between socio-demographic variables and having a medical condition ( $\mathrm{N}=148)$.

\begin{tabular}{|c|c|c|c|c|c|c|}
\hline & $\begin{array}{l}\text { With Psychiatric Comorbidity } \\
\text { n (\%) }\end{array}$ & $\begin{array}{l}\text { Without psychiatric comorbidity } \\
\qquad \text { (\%) }\end{array}$ & Total & $x^{2}$ & df & $p$ value \\
\hline \multicolumn{7}{|l|}{ Age (years) } \\
\hline $11-20$ & $5(11.4)$ & 39 (88.6) & 44 & & & \\
\hline $21-30$ & $8(16.3)$ & $41(83.7)$ & 49 & & & \\
\hline $31-40$ & $14(48.3)$ & $15(51.7)$ & 29 & & & \\
\hline $41-50$ & $9(81.8)$ & $2(18.2)$ & 11 & 40.814 & 5 & $0.000 *$ \\
\hline $51-60$ & $7(77.8)$ & $2(22.2)$ & 9 & & & \\
\hline$>60$ & $1(6.7)$ & $5(83.3)$ & 6 & & & \\
\hline \multicolumn{7}{|l|}{ Sex } \\
\hline Male & $20(29.4)$ & $48(70.6)$ & 68 & 0.006 & 1 & 0.542 \\
\hline Female & $24(30.0)$ & $56(70.0)$ & 80 & & & \\
\hline \multicolumn{7}{|l|}{ Marital Status } \\
\hline Single (Unmarried) & $21(19.8)$ & $85(80.2)$ & 106 & & & \\
\hline Separated/Divorced & $4(100)$ & $0(0)$ & 4 & 22.867 & 3 & $0.000 *$ \\
\hline Married & $17(53.1)$ & $15(46.9)$ & 32 & & & \\
\hline Widowed & $2(33.3)$ & $4(66.7)$ & 6 & & & \\
\hline \multicolumn{7}{|l|}{ Literacy } \\
\hline Illiterate & $14(32.6)$ & $29(67.4)$ & 43 & 7.522 & 3 & 0.057 \\
\hline Primary education & $8(34.8)$ & $15(65.2)$ & 23 & & & \\
\hline Secondary education & $11(18.6)$ & $48(81.4)$ & 59 & & & \\
\hline Tertiary education & $11(47.8)$ & $12(52.2)$ & 23 & & & \\
\hline *Significant at $p<0.05$ & & & & & & \\
\hline
\end{tabular}

Table 5 Association between socio-demographic variables and psychiatric comorbidity $(N=148)$.

\begin{tabular}{|c|c|c|c|c|c|c|}
\hline & $\begin{array}{l}\text { With Psychiatric Comorbidity } \\
\text { n (\%) }\end{array}$ & $\begin{array}{l}\text { Without psychiatric comorbidity } \\
\text { n (\%) }\end{array}$ & Total & $x^{2}$ & df & $p$ value \\
\hline \multicolumn{7}{|l|}{ Age (years) } \\
\hline $11-20$ & $13(29.5)$ & $31(70.5)$ & 44 & 7.068 & 5 & 0.216 \\
\hline $21-30$ & $17(34.7)$ & $32(65.3)$ & 49 & & & \\
\hline $31-40$ & $15(51.7)$ & $14(48.3)$ & 29 & & & \\
\hline $41-50$ & $5(45.5)$ & $6(54.5)$ & 11 & & & \\
\hline $51-60$ & $5(55.6)$ & $4(44.4)$ & 9 & & & \\
\hline$>60$ & $4(66.7)$ & $2(33.3)$ & 6 & & & \\
\hline \multicolumn{7}{|l|}{ Sex } \\
\hline Male & $31(45.6)$ & $37(54.4)$ & 68 & 1.719 & 1 & 0.127 \\
\hline Female & $28(35.0)$ & $52(65.0)$ & 80 & & & \\
\hline \multicolumn{7}{|l|}{ Marital Status } \\
\hline Single & 37 (34.9) & $69(65.1)$ & 106 & 4.776 & 3 & 0.189 \\
\hline Separated/Divorced & $3(75.0)$ & $1(25.0)$ & 4 & & & \\
\hline Married & $16(50.0)$ & $16(50.0)$ & 32 & & & \\
\hline Widowed & $3(50.0)$ & $3(50.0)$ & 6 & & & \\
\hline \multicolumn{7}{|l|}{ Literacy } \\
\hline Illiterate & $17(39.5)$ & $26(60.5)$ & 43 & 5.537 & 3 & 0.136 \\
\hline Primary education & $7(30.4)$ & $16(69.6)$ & 23 & & & \\
\hline Secondary education & $21(35.6)$ & $38(64.4)$ & 59 & & & \\
\hline Tertiary education & $14(60.9)$ & $9(39.1)$ & 23 & & & \\
\hline
\end{tabular}


education (39.9\%). This is in consonance with reports by other researchers $[12,14]$. Nevertheless other studies have reported higher prevalence among males $[15,16]$. Some studies have reported bimodal incidence of epilepsy with peaks during early childhood and during the 70s and 80s of life [17]. Our study is one of prevalence with the greatest proportion of subjects aged between $21-30$ years (33.1\%) and $11-20$ years $(29.7 \%)$.

Furthermore, contrary to our finding, other studies reported that, less education and low socioeconomic status are regarded as risk factors for epilepsy $[17,18]$.

Tonic-clonic seizure was the most prevalent type of seizure seen among the subjects (55.4\%). This is similar to reports from a study by Duggan et al in Uganda [19] but is at variance with results from another study by Hunter et al. in Tanzania where focal onset seizures was reported to account for $71.5 \%$ of all cases. Methodological differences of the various studies could be responsible for these varying figures.

This study reported that the most common psychiatric comorbidity is depression (16.2\%). This is in agreement with findings from several studies [14,20-25] which consistently reported the predominance of depression, closely followed by anxiety disorders in seizure patients. Fiest et al. noted that "epilepsy was significantly associated with depression and depression was observed to be highly prevalent in people with epilepsy" [26]; however, the point prevalence of depression among the general population is significantly lower than among epileptics [27]. Besides, several epidemiological large scale studies have reported rates of psychiatric co-morbidity ranging from 5.9 to $64 \%$ in epilepsy samples compared with 7 to $26.8 \%$ in nonepilepsy control samples [28-30].

Furthermore, temporal lobe seizure patients presented with the highest degree of psychiatric co-morbidity compared with other seizure types (91.7\%). The significance of psychiatric co-morbidity among seizure patients was further highlighted by Clancy et al. in their systematic review and meta-analysis, where the researchers reported the prevalence of psychosis in temporal lobe epilepsy to be $7 \%$ [31]. In this study, the association between seizure type and psychiatric co-morbidity is statistically significant. The preponderance of depression and anxiety found among the subjects is not surprising. This is because epilepsy aside from being chronic, dramatic and embarrassing; is characterized by stigma and discrimination towards the epileptic patient founded on cultural myths and superstitions. These in turn promote low self esteem and may lead to suicidal ideas and attempts.

\section{References}

1. Fisher RS, Acevado C, Arzimanoglou A, Bogaoz A, Cross JH, et al. (2014) ILAE official report: A Practical Definition of Epilepsy. Epilepsia 55: 475-482.

2. Arinzechi EO, Ogunrin OA, Nwosu CM, Nwani PO, Enwereji $\mathrm{KO}$, et al. (2016) A community-based case-control Study of prevalence and Pattern of Cognitive impairments in Patients
This study also revealed that the psychiatric co-morbidities were more common among the elderly (66.7\%), males (45.6\%), those separated or divorced (75.0\%) and those with tertiary education $(60.9 \%)$ but there was no statistically significant association between socio-demographic variables and psychiatric comorbidity.

It is equally important to highlight that even though there was no statistically significant association found between having a particular seizure type and developing another medical comorbidity that is not psychiatric, previous large scale multinational studies have reported that between $26.8 \%$ and $84 \%$ of epilepsy patients have at least one comorbid medical condition $[29,32]$ and these conditions are associated with almost every organ system in the body [29].

There was a statistically higher tendency of the elderly to develop another medical condition compared to the younger subjects. This finding is supported by other researchers who reported that sleep and concentration problems as well as the effects of deteriorating health, among many other complaints precipitate higher rates of medical co-morbid conditions in the elderly compared to the younger [33,34]. Similarly, the separated/ divorced were statistically more prone to developing medical comorbid conditions compared to the single. The effects of major adverse life changes or losses including the death of a loved one are predisposing factors for developing a chronic medical condition [34]

\section{Limitation}

This is a retrospective study. The patients were not interview first hand by the researcher. Retrospective data do not distinguish between current disorders and life time to-date diagnosis. Also issues of reliability and validity of the recorded responses of the patients on account of their mental state especially at the point of history taking raises significant concern [35]. Furthermore, the information regarding the temporal contiguity of comorbidity prior to and after the onset of epilepsy is limited.

\section{Conclusion}

Tonic-clonic seizure was the most prevalent seizure type seen but those suffering from temporal lobe epilepsy had the highest rate of psychiatric morbidity. Depression was the most common psychiatric co-morbidity among epileptic patients and seizure patients have the tendency to develop another medical condition as they grow older.

with Epilepsy Residing in South Eastern Nigeria. J Neurosci Rural Pract 7:405-411.

3. Ngugi AK, Bottomely C, Kleischmidt I, Wagner RG, KakoozaMwesige A, et al. (2013) Prevalence of Active Convulsive Epilepsy in Sub-Saharan Africa and Associated Risk Factors; Cross sectional and Case Control Studies. Lancet Neurol 12:253-263. 
4. Ngugi AK, Bottomley C, Fegan G, Chengo E, Odhiambo R, et al. (2014) Premature Mortality in Active Convulsive Epilepsy in Rural Kenya: Causes and Associated Factors. Neurology 82:582-589.

5. Mung'ala Odera V, White S, Meehan R, Otieno GO, Njuguna P, et al. (2008) Prevalence, Incidence and Risk Factors of Epilepsy in Older Children in Rural Kenya. Seizure 17:396-404.

6. Kind CJ, Newton CRJ, Kariuki SM (2017) Prevalence, Risk factors and Neuro-behavioural Co-morbidities of Epilepsy in Kenyan Children. Epilepsia Open 2:388-399.

7. Amudhan S, Gururaj G, Satishchandra P (2015) Epilepsy in India: Epidemiology and Public Health. Ann Indian Acad Neurol 18:263-277.

8. Nwani PO, Nwosu MC, Enwereji KO, Asomugha AL, Arinzechi EO, et al. (2013) Epilepsy treatment gap: Prevalence and Associated Factors in South East Nigeria. Acta Neurol Secand 128:83-90.

9. Longe AC, Osuntokun BO (1989) Prevalence of Neurological Disorders in Udo, a Rural Community in southern Nigeria. Trop Geog Med 41:36-40.

10. Osuntokun BO, Adeuja AOG, Nottidge VA, Bademosi O, Schoenberg BS, et al. (1987) Prevalence of the Epilepsies in Nigeria Africans; A Community Based Study. Epilepsia 28:272 279.

11. https://www.who.int/mental_health/management/epilepsy_ in_African-region.pdf

12. Moran NF, Poole K, Bell G, Solomon J, Kendall S, et al. (2004) Epilepsy in the United Kingdom: Seizure frequency and severity, antiepileptic drug utilization and impact on life in 1652 people with epilepsy. Seizure 13:425-433.

13. Colobunders R, Tepage F, Rood E, Mandro M, Abath EN, et al. (2016) Prevalence of River Epilepsy in the Oriental province in the democratic Republic of the Congo. PLoS Negi Trop 10:e0004478.

14. Mohammadi MR, Ghanizadeh A, Davidan H, Mohammadi M, Norouzian M (2006) Prevalence of Epilepsy and Co-morbidity of Psychiatric Disorders in Iran. Seizure 5:476-482.

15. Das SK, Biswas A, Roy T, Banerjee TK, Mukherjee CS, et al. (2006) A random sample survey for prevalence of major neurological disorders in Kolkota. Indian J Med Res 124:163-172.

16. Radhakrishnan K, Pandian JD, Santhoshumar T, Thomas JV, Dectha TD, et al. (2000) Prevalence, Knowledge, attitude and practice of epilepsy in Kerala, south India. Epilepsia 41:10271035.

17. Banerjee TK, Ray BK, Das SK, Hazra A, Ghosal MK, et al. (2010) A longitudinal study of epilepsy in Kolkata, India. Epilepsia 51:2391.

18. Joseph N, Kumar GS, Nelliyanil M (2013) Pattern of Seizure cases in tertiary care hospitals in Karnataka State of India. Ann Indian Acad Neurol 16:347-351.

19. Duggan MB (2010) Epilepsy in rural Ugandan Chidlren: Seizure pattern, age of onset and associated findings. Afr Health Sci 10:218-225.
20. Hunter E, Rogathi J, Chigudu S, Jusabani A, Jackson M, et al. (2012) Prevalence of active epilepsy in rural Tanzania: A large community-based survey in an adult population. Seizure 21:691-698

21. Takele I, Adamu B (2018) Prevalence and factors associated to Depression and Anxiety among people with epilepsy on follow up at hospital in West Shewa Zone, Oromia Reginal State, Central Ethiopia: Institution based cross-sectional study. J Psychiatr Ment Health 391: 1-7.

22. Attinoz AE, Meric OT, Altinoz ST, Essizoglu A, Cosar B (2016) Psychiatric disorders comorbid with epilepsy in a prison sample. Seizure 40:133-135.

23. Dominguez-Aguilera MC, Muniz-Landeros CE (2017) Prevalence of Psychiatric disorders in patients with epilepsy in a tertiary level care hospital. Detection through the MINI PLUS. International Structured Interview. Medicina Universitaria 19:3-6.

24. Bifftu BB, Dachew BA, Tiruneh BT, Tebeje NB (2015) Depression Among People with Epilepsy in Northern Ethiopia: A Cross Sectional Institution Based Study. BMC Res Notes 8:585.

25. Nidhinandana S, Chnvarun $Y$, Sithinamsuwan $P$, Udommongko C, Suwantamee J, et al. (2007) Prevalence of depression among epileptic patients at Phramongkutklao Hospital. J Med Assoc Thai 9:32-36.

26. Fiest KM, Dykeman J, Patten SB, Wiebe S, Kaplan GG, et al. (2013) Depression in epilepsy: A systematic review and metaanalysis. Neurology 80:590-599.

27. Shin C, Kim Y, Park S, Yoon S, Ko Y, et al. (2014) Prevalence and Associated Factors of Depression in General Population of Korea: Results From the Korea National Health and Nutritional Examination Survey 2014. J Korean Med Sci 32:1861-1869.

28. Gaitatzis A, Trimble MR, Sander JW (2004) The psychiatric comorbidity oif epilepsy. Acta Neurol Scand 110:207-220.

29. Seidenberg M, Pusipher DT, Hermann B (2009) Association of epilepsy and comorbid conditions. Future Neurol 4:663-668.

30. Tellez JF, Patten SB, Jette N, Williams J, Wiebe S (2007) Psychiatric comorbidity in epilepsy, a population based analysis. Epilepsia 48:2330-2334.

31. Clancy MJ, Clarke MC, Connor DJ, Cannon M, Cotter D (2014) The prevalence of psychosis in epilepsy; A systematic review and meta-analysis. BMC Psychiatry 14:75.

32. Strine TW, Kobau R, Chapman DP, Thurman DJ, Price P, et al. (2005) Psychological distress, comorbidities and health behaviours among US adults with seizures: Results from the 2002 national health interview survey. Epilepsia 46:1133-1139.

33. Felmet K, Zisook S, Kasckow JW (2011) Elderly patients with schizophrenia and Depression: Diagnosis and Treatment. Clin Schizophr Relat Psychoses 4:239-250.

34. Menninger JA (2002) Assessment and treatment of alcoholism and substance related disorder in the elderly. Bull Menninger Clin 66: 166-183

35. Dworkin RJ (1992) Researching Persons with mental illness. Sage Publications. 